OPEN ACCESS

Edited by:

Learn-Han Lee,

Monash University Malaysia, Malaysia

Reviewed by:

Javad Sharifi-Rad,

Shahid Beheshti University of Medical

Sciences, Iran

Floriana Campanile,

Università degli Studi di Catania, Italy

*Correspondence:

Mohammad Aminul Islam

maislam@icddrb.org

tPresent address:

Mohammad Aminul Islam,

Paul G. Allen School for Global Animal

Health, Washington State University,

Pullman, WA, United States

Mohsina Huq,

School of Science, RMIT University,

Melbourne, VIC, Australia

Ashikun Nabi,

Department of Biology, University of Vermont, Burlington, VT,

United States

Specialty section: This article was submitted to

Food Microbiology,

a section of the journal

Frontiers in Microbiology

Received: 28 August 2018

Accepted: 27 February 2019

Published: 14 March 2019

Citation:

Islam MA, Parveen S, Rahman M, Huq M, Nabi A, Khan ZUM, Ahmed N and Wagenaar JA (2019) Occurrence and Characterization of Methicillin

Resistant Staphylococcus aureus in Processed Raw Foods and Ready-to-Eat Foods in an Urban

Setting of a Developing Country. Front. Microbiol. 10:503. doi: 10.3389/fmicb.2019.00503

\section{Occurrence and Characterization of Methicillin Resistant Staphylococcus aureus in Processed Raw Foods and Ready-to-Eat Foods in an Urban Setting of a Developing Country}

\begin{abstract}
Mohammad Aminul Islam ${ }^{\text {*t }}$, Sahana Parveen ${ }^{2,3}$, Mahdia Rahman', Mohsina Huq ${ }^{1 \dagger}$, Ashikun Nabi't, Zahed Uddin Mahmood Khan ${ }^{3}$, Niyaz Ahmed ${ }^{4}$ and Jaap A. Wagenaar ${ }^{5,6}$

' Food Microbiology Laboratory, Laboratory Sciences and Services Division, International Centre for Diarrhoeal Disease Research, Bangladesh, Dhaka, Bangladesh, ${ }^{2}$ Institute of Food Science and Technology, Bangladesh Council of Scientific and Industrial Research, Dhaka, Bangladesh, ${ }^{3}$ Department of Botany, Jahangirnagar University, Dhaka, Bangladesh, ${ }^{4}$ Laboratory Sciences and Services Division, International Centre for Diarrhoeal Disease Research, Bangladesh, Dhaka, Bangladesh, ${ }^{5}$ Department of Infectious Diseases and Immunology, Utrecht University, Utrecht, Netherlands, ${ }^{6}$ Wageningen Bioveterinary Research, Lelystad, Netherlands
\end{abstract}

Infections by methicillin-resistant Staphylococcus aureus (MRSA) are gradually increasing in the community. In this study, we investigated a total of 162 food samples including 112 ready-to-eat (RTE) foods and 40 processed raw meat and fish samples collected from retail vendors in Dhaka, Bangladesh and determined the occurrence of toxigenic S. aureus and MRSA. Around $22 \%$ of samples were positive for S. aureus, RTE foods being more positive (23\%) than the processed raw meat/fish samples (18\%). Among 35 S. aureus isolates, 74\% were resistant to erythromycin, 49\% to ciprofloxacin and around $30 \%$ to oxacillin and cefoxitin. Around $37 \%$ of isolates were resistant to $\geq 3$ classes of antibiotics and $26 \%$ of isolates $(n=9)$ were identified as MRSA. Majority of the isolates were positive for enterotoxin genes (74\%), followed by pvl gene (71\%), toxic shock syndrome toxin (tsst) gene (17\%) and exfoliative toxin genes (11\%). Multi locus sequence typing (MLST) of 9 MRSA isolates identified four different types such as ST80 $(n=3)$, ST6 $(n=2)$, ST239 $(n=2)$ and ST361 $(n=2)$. spa typing of MRSA isolates revealed seven different types including t1198 $(n=2)$, t315 $(n=2)$, t037 $(n=1)$, t275 $(n=1)$, t304 $(n=1)$, t8731 $(n=1)$ and t10546 $(n=1)$. To our knowledge, this is the first report entailing baseline data on the occurrence of MRSA in RTE foods in Dhaka highlighting a potential public health risk to street food consumers.

Keywords: methicillin resistant S. aureus, raw meat, ready-to-eat foods, MLST, spa typing

\section{INTRODUCTION}

Staphylococcus aureus (SA) is present in up to $80 \%$ of healthy individuals as a commensal, yet it is one of the most common causes of skin and soft tissue infections sometimes leading to complicated infections, such as necrotizing pneumonia, septic arthritis, endocarditis, and osteomyelitis (Popovich and Hota, 2008; David and Daum, 2010). S. aureus produces various toxins 
which are often produced in the food, and consumption of intoxicated foods potentially leads to serious diseases (Abdolshahi et al., 2018). It has many cell-associated and secreted virulence factors; some of these virulence factors include Panton-Valentine leukocidin toxin (PVL), toxic shock syndrome toxin 1 (TSST-1), hemolysins, exfoliative toxins (ETs), and staphylococcal enterotoxins (SEs) (Tong et al., 2015). PVL is a cytotoxin, related to leukocyte destruction, tissue necrosis, diffuse cellulitis, skin and soft tissue infections, necrotizing pneumonia, and osteomyelitis (Lina et al., 1999). SEs cause staphylococcal food poisoning, whereas TSST-1 and ETs are responsible for toxic shock syndrome (TSS) and staphylococcal scalded-skin syndrome (SSSS), respectively (Tong et al., 2015).

Infections caused by $S$. aureus are difficult to treat due to its ability to acquire and develop resistance to multiple antibiotics. Over the past decades, the epidemiology of methicillin-resistant Staphylococcus aureus (MRSA) has changed significantly. MRSA has recently been listed as one of the high-priority antibiotic-resistant pathogens by the World Health Organization (Tacconelli et al., 2017). A majority of MRSA associated with disease in hospitalized patients is known as hospital-associated (HA)-MRSA. In the early 1990s, a new type of genetically different MRSA strains has been evolved in the community known as communityassociated (CA)-MRSA (Otto, 2010). Because of enhanced production of varieties of toxins, these CA-MRSA strains are exceptionally pathogenic (Cameron et al., 2011; Otto, 2012) compared to HA-MRSA. Furthermore, MRSA infections in the community caused by strains primarily associated with livestock is known as livestock-associated (LA)-MRSA (Nemati et al., 2008).

Apart from direct transmission to humans from animals, the latter being considered as a natural reservoir of this organism, transmission of MRSA might occur via exposure to or ingestion of contaminated foods. People having frequent contact with animal reservoirs or food contaminated with MRSA can become colonized with this organism and spread to the community. Food sampling and testing should be focused on foods of animal origin and especially the ready-to-eat (RTE) foods which require frequent manual handling for preparation and serving.

In Bangladesh, information on the prevalence of MRSA is currently scarce. Only a few surveys have been done in health care settings. One study among diabetic patients reported that around $37 \%$ of hospitalized and $22 \%$ of non-hospitalized patients were infected with MRSA (Jinnah et al., 1998). In a more recent study, the fraction of MRSA in hospitals of different cities in Bangladesh was shown to be $32-63 \%$, which is much higher than in the United States and in European countries (Haq et al., 2005). There is substantial lack of information on the prevalence of MRSA in food sources in Bangladesh. Such information is useful for better understanding of the risk of exposure to MRSA through food, particularly the RTE foods.

In this study, we determined the occurrence of $S$. aureus and MRSA in retail food samples collected from local restaurants, superstores, and street vendors in Dhaka and characterized the isolates for antibiotic resistance, toxin genes, and genetic diversity using MLST and spa typing.

\section{MATERIALS AND METHODS}

\section{Food Sample Collection}

Between 2010 and 2013, a total of 162 retail food samples including 112 RTE foods and 40 processed raw meat and fish products were collected from different locations in Dhaka city (Table 1). At least $100 \mathrm{~g}$ of each sample was bought from the vendors and collected in a sterile plastic bag. Samples were kept in an ice box $(+4$ to $8^{\circ} \mathrm{C}$ ) immediately after collection and transported to the laboratory within 3-4 h.

\section{Sample Processing}

Twenty-five grams or $\mathrm{ml}$ (for liquid) of food sample were mixed with $225 \mathrm{ml}$ of peptone saline water and homogenized. Diluted samples were spread on the Baird-Parker agar (BP) (Oxoid Ltd., Basingstoke, United Kingdom) and incubated at $37^{\circ} \mathrm{C}$ for 24 to $48 \mathrm{~h}$. After incubation, a maximum of 3 colonies showing typical characteristics of $S$. aureus (black/dark gray with lethicinase zone) were picked up and confirmed according to the procedure described earlier (International Organization for Standardization, 1999). All coagulase positive presumptive $S$. aureus isolates were confirmed with the API STAPH system (bioMérieux S.A., France) according to manufacturer's instructions.

\section{Antimicrobial Susceptibility Test}

Susceptibility to antimicrobials was determined by an agar diffusion test using commercially available antibiotic disks (Oxoid Ltd., Basingstoke, United Kingdom) as described by the Clinical Laboratory Standards Institute (CLSI) guidelines (CLSI, 2012). The antimicrobial agents used were cefoxitin, chloramphenicol, ciprofloxacin, trimethoprimsulfamethoxazole, gentamicin, tetracycline, imipenem, erythromycin, amoxicillin-clavulanic acid, and oxacillin. Isolates that showed resistance to oxacillin in disk diffusion were tested for the minimum inhibitory concentration (MIC) for oxacillin by broth dilution method described by CLSI (2012). All MRSA isolates were tested for the MIC of vancomycin by E-test (bioMérieux S.A., France).

TABLE 1 | Prevalence of $S$. aureus and MRSA in ready-to-eat (RTE) food and processed raw meat, fish, milk samples in Dhaka, Bangladesh.

\begin{tabular}{lccc}
\hline Types of samples & $\begin{array}{c}\text { No. of samples } \\
\text { tested from } \\
\text { each type of } \\
\text { food }\end{array}$ & $\begin{array}{c}\text { No. (\%) of } \\
\text { sample } \\
\text { positive for } \\
\text { S. aureus }\end{array}$ & $\begin{array}{c}\text { No. (\%) of } \\
\text { samples } \\
\text { positive for } \\
\text { MRSA }\end{array}$ \\
\hline $\begin{array}{l}\text { Raw meat and } \\
\text { meat products }\end{array}$ & 35 & $6(17.1)$ & $1(2.9)$ \\
$\begin{array}{l}\text { Raw processed fish } \\
\text { Ready-to-eat street } \\
\text { vended foods }\end{array}$ & 5 & $1(20)$ & $1(20)$ \\
$\begin{array}{l}\text { Raw and } \\
\text { pasteurized milk }\end{array}$ & 112 & $26(23.2)$ & $7(6.3)$ \\
Total & 10 & $2(20)$ & $0(0)$ \\
\end{tabular}




\section{Polymerase Chain Reaction Assays for Virulence Genes}

All S. aureus isolates were tested for a panel of virulence and pathogenic genes including the $S$. aureus thermonuclease gene (nuc) (Brakstad et al., 1992), Panton-Valentine leukocidin toxin gene ( $p v l)$ (Lina et al., 1999), staphylococcal enterotoxin genes (sea, seb, sec, sed and see) (Sharma et al., 2000), TSS toxin-1 (tsst) gene, exfoliative toxin genes (eta and etb) and methicillin resistance gene (mecA) (Mehrotra et al., 2000). DNA was extracted from bacterial isolates according to the procedure described earlier (Bollet et al., 1955).

\section{MLST and Spa Typing}

All MRSA isolates were characterized by multi locus sequence typing (MLST) according to the procedure described earlier (Enright et al., 2000). Sequence types (ST) were assigned according to the MLST database ${ }^{1}$.

For $S$. aureus protein $\mathrm{A}(s p a)$ typing, the polymorphic $\mathrm{X}$ region of the spa gene (spa) was amplified by PCR using the primers $1095 \mathrm{~F}$ and 1517R according to the procedure described earlier (Harmsen et al., 2003). spa types were assigned by using Ridom StaphType 1.4.1 software (Ridom GmbH, Würzburg, Germany²).

\section{RESULTS}

\section{Occurrence of S. aureus in Food Samples}

Of the 162 samples, 35 (22\%) were positive for S. aureus. Among these, 26 isolates were isolated from RTE foods and 9 from raw processed foods.

\section{Antibiotic Susceptibility of S. aureus}

Antibiotic susceptibility test of the S. aureus isolates showed that $74 \%$ of isolates were resistant to erythromycin, $49 \%$ to ciprofloxacin, $31 \%$ to oxacillin, $26 \%$ to cefoxitin, $20 \%$ to amoxicillin-clavulanic acid, $20 \%$ to tetracycline, $11 \%$ to

${ }^{1}$ http://www.mlst.net/

${ }^{2}$ www.spaserver.ridom.de trimethoprim-sulfamethoxazole, $6 \%$ to imipenem and $3 \%$ to gentamicin. None of the isolates were resistant to chloramphenicol (Table 2). Around 37\% $(n=13)$ of isolates were multidrug resistant (MDR) (resistant to 3 or more classes of antibiotics). MIC for oxacillin was found $\geq 8 \mu \mathrm{g} / \mathrm{ml}$ for isolates that were identified as resistant in disk diffusion method. All MRSA isolates were found to be sensitive to vancomycin.

\section{Toxigenic Characteristics of $S$. aureus}

All S. aureus isolates were positive for thermonuclease gene $(n u c)$. About $71 \%$ of isolates $(n=25)$ were positive for $p v l$ gene. More than $74 \%$ of isolates $(n=26)$ were positive for enterotoxin genes $($ sea $=26 \%, n=9$; seb $=11 \%, n=4$; sec $=49 \%, n=17$ and sed $=3 \%, n=1)$ (Table 3). In each case, a PCR product of the expected size was generated (Figure 1). The frequencies of other genes are listed in Table 3. Nine (26\%) isolates were positive for mecA gene either alone $(2.8 \%, n=1)$ or in tandem with other genes (sec-mecA-tsst1-pvl, seb-mecA, sea-mecA, sea-mecA$p v l, s e b-m e c A-p v l)$. None of the isolates were positive for see and etb genes.

\section{Identification and Characterization of MRSA}

Of the 35 S. aureus isolates, 9 (26\%) were detected as MRSA, which represents $6 \%$ of total number of food samples $(n=162)$ tested in the study. Of these 9 isolates, 6 were isolated from RTE foods mostly served in the road side small restaurants and street vendors, 2 from processed raw meat samples and 1 from processed fish sample. All but one MRSA isolates were resistant to both oxacillin and cefoxitin, with an MIC of oxacillin $\geq 16 \mu \mathrm{g} / \mathrm{ml}$. All MRSA isolates were MDR. Of the 9 MRSA isolates, 4 (44\%) were positive for $p v l$ gene, 3 isolates of each were positive for sea and seb genes, respectively and 2 isolates were positive for $s e c$ gene. Isolates positive for $p v l$ gene were positive for at least one additional enterotoxin gene (Table 4).

\section{Genotyping of MRSA}

A total of 4 sequence types (ST) were identified among 9 MRSA isolates of which 3 isolates belonged to ST80 and 2 isolates in each belonged to ST6, ST239 and ST361. A total of 7 different spa types

TABLE 2 | Antimicrobial resistance of S. aureus strains isolated from RTE food and raw food samples (processed raw meat, fish and milk) in Dhaka, Bangladesh.

\begin{tabular}{|c|c|c|c|c|}
\hline Antimicrobial Agents & $\begin{array}{l}\text { Resistant Breakpoint (zone of } \\
\text { diameter in } \mathrm{mm} \text { ) (CLSI, 2012) }\end{array}$ & \multicolumn{3}{|c|}{ No. (\%) of resistant S. aureus isolates } \\
\hline Erythromycin & $\leq 13$ & $20(77)$ & $6(66.7)$ & $26(74.3)$ \\
\hline Ciprofloxacin & $\leq 15$ & $12(46.2)$ & $5(55.6)$ & $17(48.6)$ \\
\hline Oxacillin & $\leq 10$ & $7(27)$ & $4(44.4)$ & $11(31.4)$ \\
\hline Cefoxitin & $\leq 21$ & $6(23.1)$ & $3(33.3)$ & $9(25.7)$ \\
\hline Trimethoprim- sulfamethoxazole & $\leq 10$ & $4(15.4)$ & $0(0)$ & $4(11.4)$ \\
\hline Imipenem & $\leq 13$ & $2(7.7)$ & $0(0)$ & $2(5.7)$ \\
\hline Gentamicin & $\leq 12$ & $1(3.8)$ & $0(0)$ & $1(2.9)$ \\
\hline Chloramphenicol & $\leq 12$ & $0(0)$ & $0(0)$ & $0(0)$ \\
\hline
\end{tabular}


TABLE 3 | Prevalence of different toxin genes in S. aureus isolates from RTE food and raw food samples (processed raw meat, fish and milk) in Dhaka, Bangladesh.

\begin{tabular}{|c|c|c|c|c|c|c|c|c|c|c|}
\hline \multirow[t]{3}{*}{ Sources of strain } & \multicolumn{10}{|c|}{ No. $(\%)$ of strains positive for: } \\
\hline & \multirow[t]{2}{*}{ pvl } & \multicolumn{5}{|c|}{ se } & \multirow[t]{2}{*}{ tsst-1 } & \multicolumn{2}{|c|}{ et } & \multirow[t]{2}{*}{$\operatorname{mec} A$} \\
\hline & & $a$ & $b$ & $c$ & $d$ & e & & $a$ & $b$ & \\
\hline Ready-to-eat foods ( $n=26$ ) & $21(84)$ & $6(66.7)$ & $3(75)$ & $14(82.3)$ & $0(0)$ & $0(0)$ & 5 (83.3) & $4(100)$ & $0(0)$ & $8(88.9)$ \\
\hline Raw foods $(n=9)$ & $4(16)$ & $3(33.3)$ & $1(25)$ & $3(17.6)$ & $1(100)$ & $0(0)$ & $1(16.7)$ & $0(0)$ & $0(0)$ & $1(11.1)$ \\
\hline Total $(n=35)$ & $25(71.4)$ & $9(25.7)$ & $4(11.4)$ & 17 (48.6) & $1(2.9)$ & $0(0)$ & $6(17.1)$ & $4(11.4)$ & $0(0)$ & $9(25.7)$ \\
\hline
\end{tabular}

A

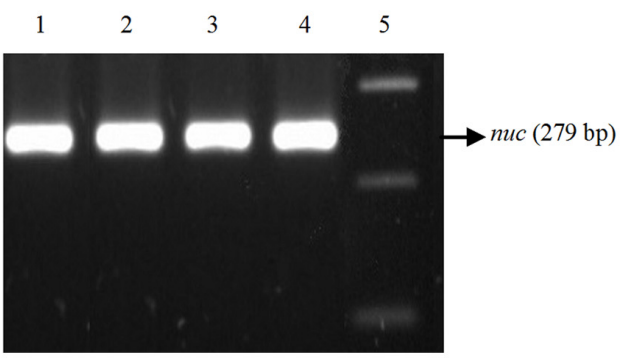

B

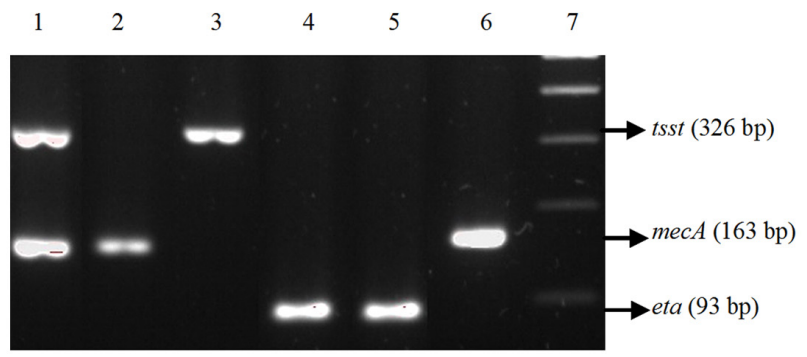

D

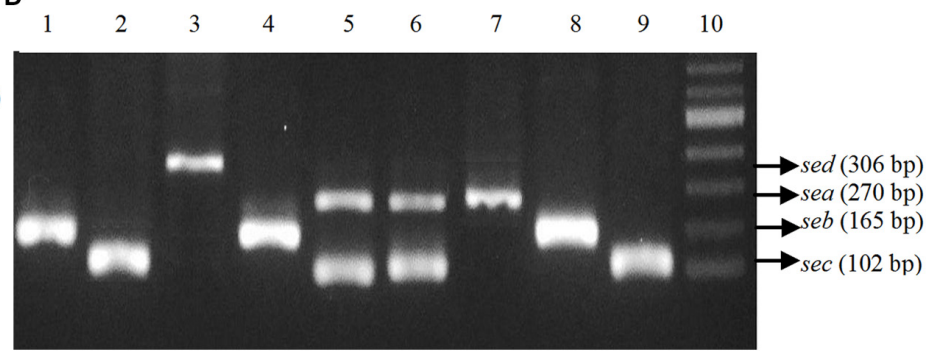

FIGURE 1 | Agarose gel electrophoresis of PCR amplified genes present in the Staphylococcus aureus isolated from RTE foods. The individual gene product was characterized by comparison with standard molecular size marker. (A) PCR for nuc gene. Lane 1-3: Samples, Lane 4: Positive Control (PC), Lane 5: 100 bp DNA ladder. (B) PCR for mecA, tsst-1 and eta genes. Lane 1: PC for mecA and tsst-1, Lane 2-4: Samples, Lane 5: PC, Lane 6: Sample, Lane 7: 100 bp DNA ladder. (C) PCR for pvl gene. Lane 1-3: Samples, Lane 4: PC, Lane 5: 100 bp ladder. (D) PCR for enterotoxin genes. Lane 1-6: Samples, Lane 7: PC for sea, Lane 8: PC for seb, Lane 9: PC for sec, Lane 10: 100 bp DNA ladder.

were detected among 9 MRSA isolates, of which t1198 and t315 were the predominant one ( 2 isolates in each type), followed by t8731, t304, t275, t10546, t037 (1 isolate in each type).

\section{DISCUSSION}

Foodborne transmission of MRSA is a global concern and therefore the prevalence and genetic characteristics of these organisms need to be thoroughly studied. This study provides the first evidence of the occurrence of MRSA in RTE food in Bangladesh. Around 23\% (26/112) of RTE food samples collected from Dhaka city were found positive for S. aureus and 5\% (6/112) were identified as MRSA. This rate is relatively higher than the reports from other countries, for example, the prevalence of MRSA in dairy products from Italy was $0.5 \%$ (Carfora et al., 2015) and $1.3 \%$ in retail foods from China (Yang et al., 2016).

Contamination of RTE foods with $S$. aureus can easily occur due to poor hygienic practices of food handlers during food preparation as it is known that $50-70 \%$ of healthy individuals serve as carriers of S. aureus (Solberg, 2000; Le Loir et al., 2003). Like many other resource poor settings, street foods in Dhaka city are often processed and served with bare hands. Although there is no data on the proportion of street food vendors in Dhaka city have $S$. aureus on their hands but a study in neighboring country India showed that $36 \%$ of hand rinse samples $(n=83)$ collected from workers responsible for food preparation, serving and cleaning, carried oxacillin resistant S. aureus (Kasturwar and Shafee, 2011). A similar study in Zimbabwe showed that $32 \%$ of food handlers carried S. aureus on their hands, while only $6.4 \%$ carried E. coli (Gadaga et al., 2008).

Clinical management of Staphylococcal infection is relied on antibiotic treatment which often fails due to aggressive resistance of organisms to antibiotics. We found that a high proportion of isolates in this study were resistant to erythromycin (74\%) and ciprofloxacin (49\%) while none of the isolates was resistant to chloramphenicol. 
TABLE 4 | Characteristics of MRSA isolated from RTE food and raw food samples (processed raw meat, fish and milk) in Dhaka, Bangladesh.

\begin{tabular}{|c|c|c|c|c|c|c|c|c|c|c|c|c|c|}
\hline \multirow{2}{*}{$\begin{array}{l}\text { Category of } \\
\text { sample }\end{array}$} & \multirow{2}{*}{$\begin{array}{l}\text { Type of } \\
\text { Sample }\end{array}$} & \multicolumn{8}{|c|}{ Toxin gene profile } & \multirow{2}{*}{$\begin{array}{l}\text { Antibiotic } \\
\text { resistance } \\
\text { pattern }^{a}\end{array}$} & \multirow{2}{*}{$\begin{array}{l}\text { MIC value of } \\
\text { oxacillin }(\leq 2=S \text {, } \\
\geq 4=R)\end{array}$} & \multirow[t]{2}{*}{ MLST } & \multirow{2}{*}{$\begin{array}{l}\text { spa } \\
\text { typing }\end{array}$} \\
\hline & & sea & seb & $\sec$ & mecA & tsst-1 & eta & etb & pvl & & & & \\
\hline $\begin{array}{l}\text { Processed raw } \\
\text { fish }\end{array}$ & Fish finger & - & - & + & + & + & - & - & - & $\begin{array}{l}\text { AMC, E, TE, CIP, } \\
\text { OX, FOX }\end{array}$ & $16 \mu \mathrm{g} / \mathrm{ml}(\mathrm{R})$ & ST 361 & $\mathrm{t} 315$ \\
\hline \multirow{2}{*}{$\begin{array}{l}\text { Processed raw } \\
\text { meat }\end{array}$} & Meat ball & - & + & - & + & - & - & - & - & AMC, E, OX, FOX & $16 \mu \mathrm{g} / \mathrm{ml}(\mathrm{R})$ & ST 80 & t8731 \\
\hline & Beef kebab & + & - & - & + & - & - & - & - & AMC, E, OX, FOX & $32 \mu \mathrm{g} / \mathrm{ml}(\mathrm{R})$ & ST 6 & t304 \\
\hline \multirow{6}{*}{$\begin{array}{l}\text { Ready-to-eat } \\
\text { foods }\end{array}$} & Burger & - & + & - & + & - & - & - & + & AMC, E, OX, FOX & $32 \mu \mathrm{g} / \mathrm{ml}(\mathrm{R})$ & ST 80 & $\mathrm{t} 1198$ \\
\hline & Pastry & - & - & - & + & - & - & - & - & $\begin{array}{l}\text { AMC, E, TE, IPM, } \\
\text { CIP, OX, FOX }\end{array}$ & $\geq 128 \mu \mathrm{g} / \mathrm{ml}(\mathrm{R})$ & ST239 & $\mathrm{t} 275$ \\
\hline & Chatpati & - & - & + & + & + & - & - & + & E, TE, CIP, OX, FOX & $32 \mu \mathrm{g} / \mathrm{ml}(\mathrm{R})$ & ST 361 & $\mathrm{t} 315$ \\
\hline & Salad & + & - & - & + & - & - & - & + & $\mathrm{E}, \mathrm{OX}$ & $16 \mu \mathrm{g} / \mathrm{ml}(\mathrm{R})$ & ST 6 & t10546 \\
\hline & Fuska & + & - & - & + & - & - & - & - & $\begin{array}{l}\text { AMC, E, TE, IPM, } \\
\text { CIP, CN, OX, FOX, } \\
\text { SXT }\end{array}$ & $\geq 128 \mu \mathrm{g} / \mathrm{ml}(\mathrm{R})$ & ST239 & t037 \\
\hline & Sweet & - & + & - & + & - & - & - & + & AMC, E, OX, FOX & $64 \mu \mathrm{g} / \mathrm{ml}(\mathrm{R})$ & ST 80 & $\mathrm{t} 1198$ \\
\hline
\end{tabular}

${ }^{a}$ AMC, Amoxicillin-clavulanic acid; E, Erythromycin; TE, Tetracycline; CIP, Ciprofloxacin; OX, Oxacillin; FOX, Cefoxitin; IPM, Imipenem; CN, Gentamicin; SXT, Trimethoprimsulfamethoxazole.

It indicates that this first generation antibiotic may serve as an alternative to the newer generation of more expensive antibiotics in resource poor settings, if infections are caused by these organisms.

Characterization of foodborne bacterial isolates for pathogenic properties provides important information on the ability of the isolates to cause human infection. We tested all $S$. aureus isolates for different pathogenic genes. We found that $p v l$ was present in $71 \%$ of all $S$. aureus and in $44 \%$ of MRSA isolates. $p v l$ is an important virulence gene of $S$. aureus, which is mainly found in clinical MRSA isolates, predominantly associated with community associated infections (CA-MRSA) (Pu et al., 2009; Hanson et al., 2011; Wang et al., 2014). The $p v l$ gene is also considered to be a stable genetic marker for CA-MRSA (Deurenberg et al., 2007). The presence of $p v l$ in large number of isolates in this study indicates the possible contamination of food via human sources and consequently contaminated food can serve as a source of CA-MRSA. Among classical enterotoxin genes, sec gene was predominantly found in S. aureus isolates (37\%) while in case of MRSA isolates, sea and seb were more common (Tables 3, 4). Epidemiological studies indicate that the majority of $S$. aureus infections and outbreaks have been caused by isolates with SEA type toxins, followed by isolates with SED, SEC and SEB toxin types (Asao et al., 2003; Ikeda et al., 2005; Cha et al., 2006; Kerouanton et al., 2007; Argudin et al., 2010). Among other toxin genes, tsst-1 (toxic shock syndrome toxin 1) and eta (an enterotoxin) were found in 17 and $9 \%$ of the S. aureus isolates, respectively. Although these toxins are mostly associated with human isolates, there are sporadic reports on the prevalence of $S$. aureus carrying these toxin genes from food sources (Hammad et al., 2012; Yang et al., 2018). Interestingly, one isolate was positive for multiple virulence genes including sec, tsst-1, eta and $p v l$ indicating the potential ability of this isolate to cause human infection.
The genetic types of all MRSA isolates were characterized by MLST and spa typing. Of the 9 MRSA isolates, 3 belonged to the Sequence Type 80 , two of these were $p v l$ positive, had the same spa type (t1198) both isolated from RTE foods but of different types and from different locations (Table 4). $p v l$ positive ST80 is predominantly found among CA-MRSA isolates in Europe and Middle East and they were associated with severe skin/soft tissue infections and necrotizing pneumonia (Budimir et al., 2010). The other genotypes found among MRSA isolates in this study were ST239-t037/t275, ST6-t304/t10546 and ST361-t315 $(n=2)$. All these genotypes were previously reported from clinical isolates of MRSA obtained from hospitalized patients. For example, the ST239-t037 was reported as the most common genotype among hospitalized burn patients in Iran and from hospitalized patients with wound/soft tissue infections and respiratory infections in Malaysia (Ghaznavi-Rad et al., 2010; Goudarzi et al., 2017). ST6t304 was reported as the predominant genotype isolated from patients with wound/soft tissue infections at a tertiary hospital in the Sultanate of Oman (Udo et al., 2014). ST239-t037 and ST6t304 clones of CA MRSA reported from Iran and Malaysia were $p v l$ negative and a majority of ST239-t037 was positive for sea gene, which is similar to the characteristics of food isolates of the same genetic types found in this study (Table 4).

In conclusion, we report the first investigation of $S$. aureus from retail, RTE foods in Dhaka, Bangladesh. The contamination of $S$. aureus was common in RTE foods with a high prevalence of MRSA. All MRSA isolates were resistant to multiple antibiotics and a majority of these were positive for more than one toxin gene indicating their pathogenic potential. Genetic types of MRSA isolates in this study matched with the epidemic and pandemic clones of CA-MRSA. Our findings therefore strongly hint at the potential role of contaminated foods in the dissemination of multi-drug resistant $S$. aureus strains. A systematic surveillance of MRSA coupled with a focused educational and awareness campaign should be undertaken along the entire food production 
and supply chain, especially targeting the sectors involved with RTE foods. Furthermore, the findings described herein could also be generally relevant to the developing country settings of Asia, Africa and all other places where RTE food is sold and consumed.

\section{AUTHOR CONTRIBUTIONS}

MI and SP developed the project and designed the research. MR, $\mathrm{MH}, \mathrm{AN}, \mathrm{ZK}$, and JW performed the experiments. MI, MR, and $\mathrm{MH}$ wrote the manuscript. All authors analyzed and discussed the data, contributed to the writing of the statement and agreed

\section{REFERENCES}

Abdolshahi, A., Naybandi-Atashi, S., Heydari-Majd, M., Salehi, B., Kobarfard, F., Ayatollahi, S. A., et al. (2018). Antibacterial activity of some Lamiaceae species against Staphylococcus aureus in yoghurt-based drink (Doogh). Cell Mol. Biol. 64, 71-77. doi: $10.14715 / \mathrm{cmb} / 2018.64 .8 .11$

International Organization for Standardization (1999). Microbiology of Food and Animal Feeding stuffs - Horizontal Method for the Enumeration of Coagulase-positive Staphylococci (Staphylococcus aureus and other species) Part 1: Technique using Baird-Parker agar Medium (EN ISO 6888-1). Geneva: International Organization for Standardization.

Argudin, M. A., Mendoza, M. C., and Rodicio, M. R. (2010). Food poisoning and Staphylococcus aureus enterotoxins. Toxins 2, 1751-1773. doi: 10.3390/ toxins 2071751

Asao, T., Kumeda, Y., Kawai, T., Shibata, T., Oda, H., Haruki, K., et al. (2003). An extensive outbreak of staphylococcal food poisoning due to low-fat milk in Japan: estimation of enterotoxin A in the incriminated milk and powdered skim milk. Epidemiol. Infect. 130, 33-40. doi: 10.1017/S0950268802007951

Bollet, C., Gevaudan, M. J., Lamballerie, X. D., Zandotti, C., and Micco, P. D. (1955). A simple method for the isolation of chromosomal DNA from Gram positive or acid-fast bacteria. Nucleic Acids Res. 19:1955. doi: 10.1093/nar/19.8. 1955

Brakstad, O. G., Aasbakk, K., and Maeland, J. A. (1992). Detection of Staphylococcus aureus by polymerase chain reaction amplification of the nuc gene. J. Clin. Microbiol. 30, 1654-1660.

Budimir, A., Deurenberg, R. H., Bosnjak, Z., Stobberingh, E. E., Cetkovic, H., and Kalenic, S. (2010). A variant of the southern german clone of methicillinresistant Staphylococcus aureus is predominant in Croatia. Clin. Microbiol. Infect. 16, 1077-1083. doi: 10.1111/j.1469-0691.2009.03042.x

Cameron, D. R., Howden, B. P., and Peleg, A. Y. (2011). The interface between antibiotic resistance and virulence in Staphylococcus aureus and its impact upon clinical outcomes. Clin. Infect. Dis. 53, 576-582. doi: 10.1093/cid/cir473

Carfora, V., Caprioli, A., Marri, N., Sagrafoli, D., Boselli, B., Giacinti, G., et al. (2015). Enterotoxin genes, enterotoxin production, and methicillin resistance in Staphylococcus aureus isolated from milk and dairy products in Central Italy. Int. Dairy J. 42, 12-15. doi: 10.1016/j.idairyj.2014.10.009

Cha, J. O., Lee, J. K., Jung, Y. H., Yoo, J. I., Park, Y. K., Kim, B. S., et al. (2006). Molecular analysis of Staphylococcus aureus isolates associated with staphylococcal food poisoning in South Korea. J. Appl. Microbiol. 101, 864-871. doi: $10.1111 / j .1365-2672.2006 .02957 . x$

CLSI (2012). Performance Standards for Antimicrobial Disk Susceptibility Tests, Approved Standard, CLSI document M02-A11, 7th Edn. Wayne, PA: Clinical and Laboratory Standards Institute.

David, M. Z., and Daum, R. S. (2010). Community-associated methicillin-resistant Staphylococcus aureus: epidemiology and clinical consequences of an emerging epidemic. Clin. Microbiol. Rev. 23, 616-687. doi: 10.1128/CMR.00081-09

Deurenberg, R. H., Kalenic, S., Friedrich, A. W., van Tiel, F. H., and Stobberingh, E. E. (2007). Molecular epidemiology of methicillin-resistant Staphylococcus aureus. Commun. Curr. Res. Educ. Top. Trends Appl. Microbiol. 2, 766-777. with its content and conclusions, and read and approved the final manuscript.

\section{FUNDING}

This research study was funded by International Centre for Diarrhoeal Disease Research, Bangladesh (icddr,b). icddr,b gratefully acknowledge the following donors, who provided unrestricted support: Government of the People's Republic of Bangladesh, Canadian International Development Agency (CIDA), and the Department for International Development, United Kingdom (DFID).

Enright, M. C., Day, N. P., Davies, C. E., Peacock, S. J., and Spratt, B. G. (2000). Multilocus sequence typing for characterization of methicillin-resistant and methicillin-susceptible clones of Staphylococcus aureus. J. Clin. Microbiol. 38, 1008-1015.

Gadaga, T. H., Samende, B. K., Musuna, C., and Chibanda, D. (2008). The microbiological quality of informally vended foods in Harare, Zimbabwe. Food Control 19, 829-832. doi: 10.1016/j.foodcont.2007.07.016

Ghaznavi-Rad, E., Nor Shamsudin, M., Sekawi, Z., Khoon, L. Y., Aziz, M. N., Hamat, R. A., et al. (2010). Predominance and emergence of clones of hospitalacquired methicillin-resistant Staphylococcus aureus in Malaysia. J. Clin. Microbiol. 48, 867-872. doi: 10.1128/JCM.01112-09

Goudarzi, M., Bahramian, M., Satarzadeh Tabrizi, M., Udo, E. E., Figueiredo, A. M., Fazeli, M., et al. (2017). Genetic diversity of methicillin resistant Staphylococcus aureus strains isolated from burn patients in Iran: ST239-SCCmec III/t037 emerges as the major clone. Microb. Pathog. 105, 1-7. doi: 10.1016/j.micpath. 2017.02.004

Hammad, A. M., Watanabe, W., Fujii, T., and Shimamoto, T. (2012). Occurrence and characteristics of methicillin-resistant and -susceptible Staphylococcus aureus and methicillin-resistant coagulase-negative staphylococci from Japanese retail ready-to-eat raw fish. Int. J. Food Microbiol. 156, 286-289. doi: 10.1016/j.ijfoodmicro.2012.03.022

Hanson, B. M., Dressler, A. E., Harper, A. L., Scheibel, R. P., Wardyn, S. E., Roberts, L. K., et al. (2011). Prevalence of Staphylococcus aureus and methicillin-resistant Staphylococcus aureus (MRSA) on retail meat in Iowa. J. Infect. Public Health 4, 169-174. doi: 10.1016/j.jiph.2011.06.001

Haq, J. A., Rahman, M. M., Asna, S. M., Hossain, M. A., Ahmed, I., Haq, T., et al. (2005). Methicillin-resistant Staphylococcus aureus in Bangladesh-a multicentre study. Int. J. Antimicrob. Agents 25, 276-277. doi: 10.1016/j. ijantimicag.2005.01.004

Harmsen, D., Claus, H., Witte, W., Rothgänger, J., Claus, H., Turnwald, D., et al. (2003). Typing of methicillin-resistant Staphylococcus aureus in a university hospital setting by using novel software for spa repeat determination and database management. J. Clin. Microbiol. 41, 5442-5448. doi: 10.1128/JCM.41. 12.5442-5448.2003

Ikeda, T., Tamate, N., Yamaguchi, K., and Makino, S. (2005). Mass outbreak of food poisoning disease caused by small amounts of staphylococcal enterotoxins A and H. Appl. Environ. Microbiol. 71, 2793-2795. doi: 10.1128/AEM.71.5.27932795.2005

Jinnah, F., Chowdhury, K., Begum, J., Sohail, M., Rahman, M. T., Ahmed, S., et al. (1998). Multi-resistant Staphylococcus aureus isolated from the wound of diabetic patients. J. Infect. Dis. Antimicrob. Agents 15, 15-18.

Kasturwar, N. B., and Shafee, M. (2011). Knowledge, practices and prevalence of MRSA among food handlers. Int. J. Biol. Med. Res. 2, 889-894.

Kerouanton, A., Hennekinne, J. A., Letertre, C., Petit, L., Chesneau, O., Brisabois, A., et al. (2007). Characterization of Staphylococcus aureus strains associated with food poisoning outbreaks in France. Int. J. Food Microbiol. 115, 369-375. doi: 10.1016/j.ijfoodmicro.2006.10.050

Le Loir, Y., Baron, F., and Gautier, M. (2003). Staphylococcus aureus and food poisoning. Genet. Mol. Res. 2, 63-76. 
Lina, G., Piemont, Y., Godail-Gamot, F., Bes, M., Peter, M. O., Gauduchon, V., et al. (1999). Involvement of panton-valentine leukocidin-producing Staphylococcus aureus in primary skin infections and pneumonia. Clin. Infect. Dis. 29, 11281132. doi: $10.1086 / 313461$

Mehrotra, M., Wang, G., and Johnson, W. M. (2000). Multiplex PCR for detection of genes for Staphylococcus aureus enterotoxins, exfoliative toxins, toxic shock syndrome toxin 1, and methicillin resistance. J. Clin. Microbiol. 38, 1032-1035.

Nemati, M., Hermans, K., Lipinska, U., Denis, O., Deplano, A., Struelens, M., et al. (2008). Antimicrobial resistance of old and recent Staphylococcus aureus isolates from poultry: first detection of livestock-associated methicillin resistant strain ST398. Antimicrob. Agents Chemother. 52, 3817-3819. doi: 10.1128/AAC. 00613-08

Otto, M. (2010). Basis of virulence in community-associated methicillin resistant Staphylococcus aureus. Annu. Rev. Microbiol. 64, 143-162. doi: 10.1146/ annurev.micro.112408.134309

Otto, M. (2012). MRSA virulence and spread. Cell Microbiol. 14, 1513-1521. doi: $10.1111 / \mathrm{j} .1462-5822.2012 .01832 . x$

Popovich, K. J., and Hota, B. (2008). Treatment and prevention of communityassociated methicillin-resistant Staphylococcus aureus skin and soft tissue infections. Dermatol. Ther. 21, 167-179. doi: 10.1111/j.1529-8019.2008.00188.x

$\mathrm{Pu}, \mathrm{S}$., Han, F., and Ge, B. (2009). Isolation and characterization of methicillinresistant Staphylococcus aureus strains from louisiana retail meats. Appl. Environ. Microbiol. 75, 265-267. doi: 10.1128/AEM.01110-08

Sharma, N. K., Rees, C. E. D., and Dodd, C. E. R. (2000). Development of a singlereaction multiplex PCR toxin typing assay for Staphylococcus aureus strains. Appl. Environ. Microbiol. 66, 1347-1353. doi: 10.1128/AEM.66.4.1347-1353. 2000

Solberg, C. O. (2000). Spread of Staphylococcus aureus in hospitals: causes and prevention. Scand. J. Infect. Dis. 32, 587-595. doi: 10.1080/003655400459478

Tacconelli, E., Carrara, E., Savoldi, A., Kattula, D., and Burkert, F. (2017). Global Priority list of Antibiotic-Resistant Bacteria to Guide Research, Discovery, and Development of new Antibiotics. Available at: http://www.cdc.gov/ drugresistance/threat-report-2013/
Tong, S. Y., Davis, J. S., Eichenberger, E., Holland, T. L., and Fowler, V. G. Jr. (2015). Staphylococcus aureus infections: epidemiology, pathophysiology, clinical manifestations, and management. Clin. Microbiol. Rev. 28, 603-661. doi: 10.1128/CMR.00134-14

Udo, E. E., Al-Lawati, B. A., Al-Muharmi, Z., and Thukral, S. S. (2014). Genotyping of methicillin-resistant Staphylococcus aureus in the sultan qaboos university hospital, oman reveals the dominance of panton-valentine leucocidin-negative ST6-IV/t304 clone. New Microbes New Infect. 2, 100-105. doi: 10.1002/ nmi2.47

Wang, X., Li, G., Xia, X., Yang, B., Xi, M., and Meng, J. (2014). Antimicrobial susceptibility and molecular typing of methicillin-resistant Staphylococcus aureus in retail foods in Shaanxi, China. Foodborne Pathog. Dis. 11, 281-286. doi: 10.1089/fpd.2013.1643

Yang, X., Yu, S., Wu, Q., Zhang, J., Wu, S., and Rong, D. (2018). Multilocus Sequence typing and virulence-associated gene profile analysis of Staphylococcus aureus isolates from retail ready-to-eat food in china. Front. Microbiol. 9:197. doi: 10.3389/fmicb.2018.00197

Yang, X., Zhang, J., Yu, S., Wu, Q., Guo, W., Huang, J., et al. (2016). Prevalence of Staphylococcus aureus and methicillin-resistant Staphylococcus aureus in retail ready-to-eat foods in china. Front. Microbiol. 7:816. doi: 10.3389/fmicb.2016. 00816

Conflict of Interest Statement: The authors declare that the research was conducted in the absence of any commercial or financial relationships that could be construed as a potential conflict of interest.

Copyright (c) 2019 Islam, Parveen, Rahman, Huq, Nabi, Khan, Ahmed and Wagenaar. This is an open-access article distributed under the terms of the Creative Commons Attribution License (CC BY). The use, distribution or reproduction in other forums is permitted, provided the original author(s) and the copyright owner(s) are credited and that the original publication in this journal is cited, in accordance with accepted academic practice. No use, distribution or reproduction is permitted which does not comply with these terms. 